conducted to determine the association between baseline subject comorbidities, clot characteristics and reperfusion, with a focus on imaging findings. The plan for per pass analysis both by an independent core imaging laboratory and by an independent clot analysis laboratory sets apart this registry from other similar studies. In addition, the reperfusion assessment by the independent core lab will be using innovative eTICI.

Disclosures A. Siddiqui: 1; C; Co-investigator NIH/NINDS 1R01NS091075. 2; C; Amnis Therapeutics, Boston Scientific, Canon Medical Systems USA Inc, Cerebrotech Medical Systems, Cerenovus, Corindus Inc., Endostream Medical Ltd, Guidepoint Global Consulting, Imperative Care, Integra LifeSciences Corp, Medtronic, MicroVention, Q’Apel Medical Inc, Rapid Medical, Rebound Therapeutics Corp., Serenity Medical Inc, Silk Road Medical, StimMed, Stryker, Three Rivers Medical, VasSol, W.L. Gore \& Associates. 4; C; Amnis Therapeutics, Apama Medical, Blink TBI Inc, Buffalo Technology Partners Inc, Cardinal Consultants, Cerebrotech Medical Systems, Cognition Medical, Endostream Medical Ltd, Imperative Care, International Medical Distribution Partners, Neurovascular Diagnostics Inc, Q'Apel Medical Inc, Rebound Therapeutics Corp, Rist Neurovascular In, Serenity Medical, Silk Road Medical, StimMed, Synchron, Three Rivers Medical Inc, Viseon Spine. T. Andersson: 2; C; Neuravi, Ablynx, Amnis Therapeutics, Medtronic, Rapid Medical, Stryker. S. De Meyer: None. K. Doyle: None. J. Fiehler: None. W. Hacke: None. R. Hanel: 2; C; Three Rivers Medical, Medtronic, Microvention, Codman, Stryker. T. Jovin: 2; C; Neuravi, codman, Medtronic, Stryker, Silk Road, Anaconda, Blockade Medical. D. Kallmes: None. D. Liebeskind: None. A. Yoo: 2; C; Cerenovus. O. Zaidat: 2; C; Stryker, Medtronic, Neuravi, Penumbra. R. Nogueria: 2; C; Neuravi, Medtronic, Penumbra, Stryker.

\section{P-010 SELECTIVE POSTERIOR CEREBRAL ARTERY AMOBARBITAL TEST: A PREDICTOR OF MEMORY FOLLOWING SUBTEMPORAL SELECTIVE AMYGDALOHIPPOCAMPECTOMY}

J Catapano*, A Whiting, D Wang, M Labib, V Fredrickson, K Smith, A Ducruet, F Albuquerque. Neurosurgery, Barrow Neurological Institute, Phoenix, AZ

\subsection{6/neurintsurg-2019-SNIS.46}

Introduction Selective Posterior Cerebral Artery Amobarbital Test (PCA WADA) has been used to predict post-operative memory impairment following temporal epilepsy surgery in patients that have previously failed a traditional intracarotid artery amobarbital test (ICA WADA).

Methods We retrospectively reviewed medical records from 2012 to 2018 for all patients with seizures who underwent selective PCA WADA at our institution, following either failed or inconclusive ICA WADA. Standardized neuropsychological testing was performed prior and during the WADA procedure, as well as post-surgery in patients who underwent resection.

Results A total of 33 patients underwent a selective PCA WADA, with no complications recorded. 26 patients with medically-refractory epilepsy were determined to have a seizure focus amendable to selective amygdalohippocampectomy following extensive EEG monitoring. Of these 26 patients, 6 (23\%) patients had a failed PCA WADA and did not undergo selective amygdalohippocampectomy. Another 7 patients (27\%) declined surgical resection, leaving 13 patients who underwent subtemporal selective amygdalohippocampectomy. Hippocampal sclerosis was found in all 13 patients (100\%) upon pathological examinations. 12 patients (92\%) subsequently had formal neuropsychological testing and all were found to have stable memory relative to preoperative examination. 10 patients (77\%) were seizure free and had an Engle Grade of I with average follow up of 13 months.

Conclusion Selective PCA WADA is predictive of memory outcomes following a subtemporal selective amygdalohippocampectomy in patients with either a failed or inconclusive ICA WADA. Furthermore, given the low risk of complication and great potential benefit of seizure freedom, A selective PCA Wada may be warranted in medically intractable epilepsy patients that are candidates for a selective amygdalohippocampectomy with a prior failed or inconclusive ICA WADA.

Disclosures J. Catapano: None. A. Whiting: None. D. Wang: None. M. Labib: None. V. Fredrickson: None. K. Smith: None. A. Ducruet: None. F. Albuquerque: None.

\section{P-011 INCREASED RATES OF SUCCESSFUL FIRST PASS RECANALIZATION DURING MECHANICAL THROMBECTOMY FOR M2 OCCLUSIONS: A SINGLE INSTITUTION STUDY}

${ }^{1} \mathrm{H}$ Baharvahdat, ${ }^{2} \mathrm{~A}$ Mowla, ${ }^{2} \mathrm{~J}$ Jones, ${ }^{2} \mathrm{Y}$ Ooi, ${ }^{2} \mathrm{~N}$ Kaneko, ${ }^{2} \mathrm{R}$ Jahan, ${ }^{2} \mathrm{~S}$ Tateshima, ${ }^{2} \mathrm{~V}$ Szeder, ${ }^{2} \mathrm{M}$ Nour, ${ }^{2} \mathrm{~F}$ Vinuela, ${ }^{2} \mathrm{G}$ Duckwiler, ${ }^{1} \mathrm{G}$ Colby*. ${ }^{1}$ Neurosurgery, UCLA, Los Angeles, CA; ${ }^{2}$ Radiology, UCLA, Los Angeles, CA

\subsection{6/neurintsurg-2019-SNIS.47}

Background Mechanical thrombectomy (MT) is standard of care for treatment of acute ischemic stroke due to proximal anterior circulation large vessel occlusion, such as the M1 segment of the middle cerebral artery (MCA). The effectiveness and complication profile in more distal vessels such as the M2 segment, however, remains to be completely defined.

Methods All MT treatments for acute M1 or M2 occlusion between 2011 and 2018 were retrospectively reviewed. Patients with thrombectomy using Merci device, intra-arterial pharmacological thrombolysis, mechanical wire maceration, or only using a balloon were excluded. Patient characteristics (age, NIHSS), number of passages, first passage recanalization success (TICI $2 \mathrm{~b}$ or higher), total recanalization success, and hemorrhagic complications (ICH and SAH) were compared between M1 and M2 groups.

Results Two hundred sixty cases, including 171 M1 and 89 M2 occlusions, were analyzed. The mean age of patients and median of NIHSS were $70.7 \pm 15.0$ (SD) years and 15 (1$33)$, respectively. There was no significant difference between M1 and M2 groups for age and NIHSS $(p=0.727$ and $p=$ 0.065 , respectively). The total number of passages in M2 group was significantly less than M1 group (Median of 1 and range of 1 to 5 versus median of 2 and range of 1 to 7 , $\mathrm{p}=0.023)$. First passage recanalization success rate was significantly higher in the M2 group than the M1 group $(55.1 \%$ versus $39.2 \%, \mathrm{p}=0.015)$. The total recanalization success rate also trended higher in the M2 group, but it did not reach statistical significance $(83 \%$ versus $74.7 \%, p=0.132)$. Subarachnoid hemorrhage rate was significantly higher in the M2 group than the M1 group (24.7\% versus $12.3 \%, \mathrm{p}=0.010)$, but there was no difference for $\mathrm{ICH}$ between the two groups $(\mathrm{p}=0.862)$.

Conclusion Mechanical thrombectomy for M2 occlusions is effective, has a higher rate of first pass recanalization, and has 